\title{
Blood-Brain Barrier Permeability to Bilirubin in the Rat Studied Using Intracarotid Bolus Injection and in Situ Brain Perfusion Techniques
}

\author{
N. K. IVES AND R. M. GARDINER \\ Department of Paediatrics, School of Medicine, University College London, The Rayne Institute, University \\ Street, London, WCIE 6JJ, United Kingdom
}

\begin{abstract}
It has generally been assumed that free unconjugated bilirubin gains access to the brain because of its lipid solubility. However, no measurements of the bloodbrain barrier permeability to free bilirubin exist. The aim of these experiments was to determine the blood-brain barrier permeability in the rat to free bilirubin using singlepass (Oldendorf) and in situ perfusion (Takasato) techniques. Studies were performed on adult rats under sodium pentobarbitone anesthesia. $\left[{ }^{3} \mathrm{H}\right]$ bilirubin IX- $\alpha-\mathrm{ZZ}$ (sp act $6.2 \mathrm{Ci} / \mathrm{mmol}$ ) was synthesized by reduction of biliverdin with sodium boro- $\left[^{3} \mathrm{H}\right]$ hydride. Blood-brain barrier permeability to albumin-bound and free bilirubin was determined using injectates/perfusates containing a molar excess of human serum albumin with or without the addition of the displacing agent sulphadimethoxine. For free bilirubin, the brain uptake index was $28.5 \pm 9.3$ (mean $\pm \mathrm{SD}, n=18$ ), and the permeability surface area product was $54.84 \pm$ $36.38 \times 10^{-4} \mathrm{~mL} / \mathrm{s} / \mathrm{g}$ (mean $\pm \mathrm{SD}, n=13$ ). These results demonstrate that the behavior of free bilirubin in vivo in relation to the cerebral microvasculature corresponds to that of a "lipid soluble" molecule. (Pediatr Res 27: 436441, 1990)
\end{abstract}

\section{Abbreviations}

BUI, brain uptake index

PA, permeability surface area product

In humans and other mammals, metabolism of the heme component of $\mathrm{Hb}$ generates the linear tetrapyrrole bilirubin. In man, the naturally occurring form of this compound is bilirubin IX- $\alpha$-ZZ. It circulates bound to albumin and, under physiologic conditions, the concentration of unbound bilirubin is very low. Conjugation by esterification with glucuronyl groups in the liver allows its excretion in bile.

Serum levels of unconjugated bilirubin frequently rise above normal in human newborns. This neonatal jaundice is a concern in the medical care of newborn infants because of its association with neurotoxicity. The bilirubin encephalopathy associated with high serum levels of bilirubin implies that this molecule gains access to the CNS.

The mode of entry of bilirubin into the brain remains uncertain. Initially, it was suggested that the susceptibility of the newborn to bilirubin neurotoxicity reflects the increased permeability of an "immature" blood-brain barrier. However, available

Received August 7, 1989: accepted December 15, 1989.

Correspondence: Dr. N. K. Ives, Department of Paediatrics, University of Oxford, John Radcliffe Hospital, Headington, Oxford OX3 9DU, United Kingdom. Supported by Birthright. The National Fund for Research into Crippling Diseases, and the Medical Research Council, UK. evidence indicates that the blood-brain barrier in humans is "tight" to macromolecules from an early stage in gestation (1).

It is now generally assumed that bilirubin crosses the bloodbrain barrier because of its lipid solubility, but there is no direct evidence for this contention. Although intramolecular hydrogenbonding masks polar groups and drastically reduces the aqueous solubility of bilirubin, especially when protonated as the acid, the molecule has very low solubility in nonpolar solvents such as ether (2). It is therefore not lipid soluble in the generally accepted sense. However, there is no doubt that it does have a high affinity for membrane lipids (2).

Diamond and Schmid (3) attempted to measure permeability of the blood-brain barrier to free bilirubin, and their study is generally cited as evidence for the "free bilirubin" hypothesis. However, these experiments did not include measurement of free bilirubin levels, and no attempt at quantitation was made.

The aim of our experiments was to quantify the transfer of bilirubin from blood to brain in the adult rat under conditions in which the relative proportions of free and albumin-bound bilirubin could be controlled and defined. The intracarotid bolus injection and in situ brain perfusion techniques were used. Evidence was obtained that the blood-brain barrier in the cerebral hemisphere of the adult rat is permeable to free bilirubin.

\section{MATERIALS AND METHODS}

Surgical Procedure. Studies were performed on adult male rats (Wistar strain), body wt 300-500 g. The rats had free access to a standard diet and water before surgery. Anesthesia was induced with halothane (Fluothane, ICI, Macclesfield, England), and maintained with sodium pentobarbitone (Sagatal, May \& Baker Ltd, Dagenham, England) given initially as an intraperitoneal dose of $50 \mathrm{mg} / \mathrm{kg}$ body wt and thereafter intravenously at intervals. The left femoral artery and vein were cannulated, and arterial blood pressure was monitored continuously. Tracheostomy was performed and intermittent positive pressure ventilation instituted to maintain normal respiratory blood gas tensions. The right external carotid artery was exposed and clamped proximally during surgery. After ligation of the superior thyroid branch, it was retrogradely cannulated with polythene tubing (Portex, Hythe, England; outer diameter $0.8 \mathrm{~mm}$, inner diameter $0.4 \mathrm{~mm}$, length $15 \mathrm{~cm}$ ) such that the tip was sited 2-4 mm distal to the bifurcation of the common carotid artery (Fig. 1a). Care was taken not to interrupt flow to the right internal carotid at any time during surgery. Cannulae were kept patent with heparinized normal saline ( $2 \mathrm{IU}$ sodium heparin $/ \mathrm{mL}$ saline). In the case of in situ brain perfusion studies, the right common carotid artery was prepared for ligation by loosely encircling the artery with surgical thread (Fig. 1b). Surgery was performed on a heated operating table adjusted to maintain the animal's rectal temperature at $37.0 \pm 0.5^{\circ} \mathrm{C}$. Uptake studies were terminated by decapitation at $5 \mathrm{~s}$ in single-pass studies and at $60 \mathrm{~s}$ in brain perfusion 
(a)

(b)

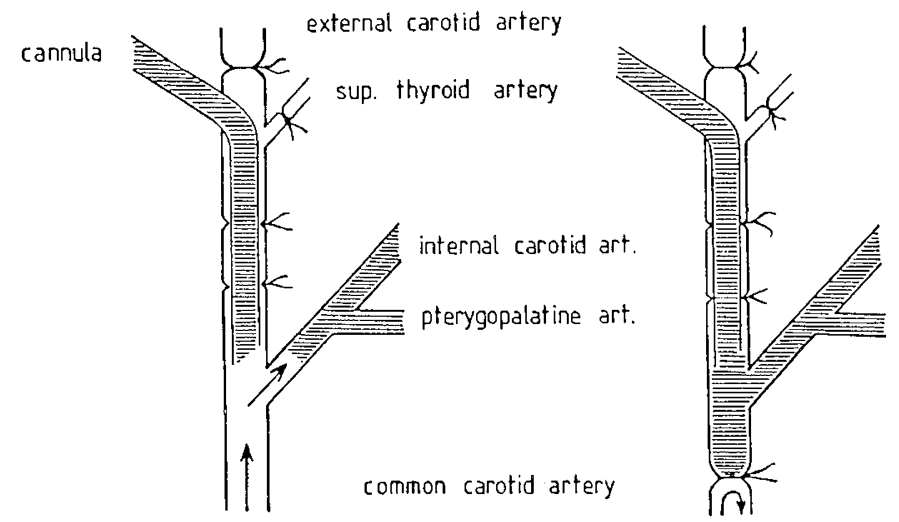

Fig. 1. External carotid artery cannulation for $(a)$ single-pass studies in which the injectate bolus is carried through the cerebral circulation by uninterrupted common carotid artery flow and $(b)$ in situ perfusion where the common carotid artery is ligated immediately before infusion.

experiments using a guillotine (Harvard Instruments, Boston, MA).

Radiochemicals. Butanol, N-[1- $\left.{ }^{14} \mathrm{C}\right]-(\mathrm{sp}$ act $1.0 \mathrm{mCi} / \mathrm{mmol}$, New England Nuclear, Boston, MA). ${ }^{99 \mathrm{~m}} \mathrm{Tc}$ as sodium pertechnetate (Elumatic III ${ }^{99 \mathrm{~m}} \mathrm{Tc}$ generator, International-CIS, St. Quentin-Yveslines Cedex, France). D-[U- $\left.{ }^{14} \mathrm{C}\right]$-alanine (sp act 20 $\mathrm{mCi} / \mathrm{mmol}$, Amersham International Corp., Arlington Heights, IL). Bilirubin of sufficiently high sp act was not available commercially. $\left.{ }^{3} \mathrm{H}\right]$ Bilirubin IX $-\alpha(\mathrm{sp}$ act $6.2 \mathrm{Ci} / \mathrm{mmol})$ was therefore specially prepared in collaboration with Amersham International's tritium-labeling service (TR5), as follows: crystalline bilirubin (Sigma Chemical Co., St. Louis, MO, cat. no. B4126) was purified by the method of McDonagh and Assisi (4), and used in the preparation of purified biliverdin as described by McDonagh and Palma (5). Purified biliverdin (4 $\mathrm{mg}$ dissolved in $1 \mathrm{~mL}$ methanol) was reduced with sodium boro- $\left[{ }^{3} \mathrm{H}\right]$-hydride $(0.6 \mathrm{mg}$ solid, sp act $50 \mathrm{Ci} / \mathrm{mmol})$, using an adaptation of the method described by Hutchinson et al. (6). The reagents were stirred in darkness under nitrogen at room temperature for $15 \mathrm{~min}$. The reaction was halted with $10 \mathrm{~mL}$ glycine hydrochloride buffer, $\mathrm{pH}$ 2.8 , and the product extracted with chloroform $(10 \mathrm{~mL} \times 3)$. Unincorporated tritium was removed by rotary evaporation after the addition of methanol. The product was pumped to dryness, sealed under argon in a glass ampoule, and transported to University College, London at $-20^{\circ} \mathrm{C}$. The $\left[{ }^{3} \mathrm{H}\right]$ bilirubin was retrieved in chloroform $(15 \mathrm{~mL})$ and reduced in volume to 0.8 $\mathrm{mL}$ before purification by thin-layer chromatography to remove the isomers III- $\alpha$ and XIII- $\alpha$ (Merck TLC silica gel $(\mathrm{H})$ plates activated at $120^{\circ} \mathrm{C}$ for $60 \mathrm{~min}$, and developed under argon with $1 \%$ glacial acetic in analytical reagent chloroform). The bilirubin IX- $\alpha$ band was eluted from the plate and extracted from the silica gel by washing with chloroform and centrifugation $(\times 3)$. $\left[{ }^{3} \mathrm{H}\right]$ Bilirubin IX- $\alpha$ (sp act $\left.6.2 \mathrm{Ci} / \mathrm{mmoL}\right)$ was stored dry in aliquots of $0.25-2.0 \mathrm{nmol}$, under argon in sealed ampoules at $-20^{\circ} \mathrm{C}$ in the dark.

Preparation of Injectates/Perfusates. Despite the optimal storage conditions used, the radiochemical purity of stock $\left[{ }^{3} \mathrm{H}\right]$ bilirubin had declined to $90 \%$ at the time of these experiments. After the addition of a 20 -fold $M$ excess of albumin to effectively bind all bilirubin, approximately $10 \%$ of the tritium activity remained dialyzable, indicating that it was not associated with bilirubin. A further purification process was therefore adopted immediately before its use. $\left[{ }^{3} \mathrm{H}\right]$ Bilirubin was retrieved from storage ampoules in a solution of $0.1 \mathrm{M}$ sodium hydroxide and $5 \mathrm{mM}$ EDTA, 0.4-0.8 $\mathrm{mL}$. Human serum albumin (Kabi, Uxbridge, England), $0.8-1.6 \mathrm{~mL}$, at $\mathrm{pH} 9$ to prevent aggregation of bilirubin, was added in 20 -fold $\mathrm{M}$ excess. The $\mathrm{pH}$ was adjusted to between 7.5 and 8.0 by addition of $0.5 \mathrm{M} \mathrm{HCl}$. Unincorporated tritium was then removed by membrane dialysis against Ringer's saline, $\mathrm{pH} 7.5$, gently agitated for $18 \mathrm{~h}$ at room temperature, in the dark. Visking tubing with a mol wt cutoff of $12000-14000$ was used to dialyze 1 vol of albumin-bound bilirubin against 1 000 vol Ringer's saline. The use of albumin-binding to facilitate purification made it necessary to add a displacing agent to study free bilirubin uptake. The sulfonamide sulfadimethoxine (Madribon, Roche, Welwyn Garden City, England), which displaces bilirubin from its primary binding site on albumin, was used.

Sufficient dialyzed $\left[{ }^{3} \mathrm{H}\right]$ bilirubin was prepared to perform up to six experiments. Half was used to study the uptake of albuminbound bilirubin, and sulfadimethoxine was added to the remainder for free bilirubin studies. Sulfadimethoxine was added at a concentration of $10 \mathrm{mmol} / \mathrm{L}$ to injectates and $5 \mathrm{mmol} / \mathrm{L}$ to perfusates. The efficiency of the purification process and the amount of $\left[{ }^{3} \mathrm{H}\right]$ bilirubin displaced from albumin by the sulfonamide were determined by centrifugation of samples of the injectate/perfusate, at the time of individual uptake studies, using Centriflo membrane cones (type CF25, Amicon Corp., Danvers, MA) operating below the maximum recommended relative centrifugal force of $1000 \times g$, at room temperature.

The $\mathrm{pH}$ of the solutions was measured before use and the concentration of bilirubin in injectates and perfusates was calculated from the known sp act of the $\left[{ }^{3} \mathrm{H}\right]$ bilirubin used.

Experimental Procedure. Single-pass studies. The BUI for bilirubin was measured using an adaptation of the method originally described by Oldendorf (7). The injectate was delivered via a cannula placed retrogradely in the external carotid artery as described by Hardebo and Nilsson (8) rather than by direct puncture of the common carotid artery (Fig. 1a). The isotope composition of injectates was $0.4-1.0 \mu \mathrm{Ci}\left[{ }^{3} \mathrm{H}\right]$ bilirubin, $0.1-$ $0.25 \mu \mathrm{Ci}\left[{ }^{14} \mathrm{C}\right]$ butanol, and $10 \mu \mathrm{Ci}{ }^{99 \mathrm{~m}} \mathrm{Tc}$ as sodium pertechnetate. Butanol was used as a freely diffusible internal reference, almost completely extracted by the brain during a single passage, and sodium pertechnetate, which is nondiffusible, enabled correction for the background intravascular space. The osmolality of the injectates was $160-245 \mathrm{mosmol} / \mathrm{kg}$, and the $\mathrm{pH}$ was $7.8-$ 8.3. In the case of free bilirubin uptake studies, an intraperitoneal loading dose of $200 \mathrm{mg} / \mathrm{kg}$ of sulfafurazole was given to minimize the effect of any mixing between the injectate and rat plasma.

The injectate was infused as a $200 \mu \mathrm{L}$ bolus over $1 \mathrm{~s}$ and decapitation performed after $5 \mathrm{~s}$. Aliquots of the injectate and brain tissue samples from the frontal, parietal, and occipital lobes of the ipsilateral cerebral hemisphere were prepared for immediate $\gamma$ counting (Packard Auto-Gamma Spectrometer, model 3003, Packard, Cavesham, Berkshire, England), and, following digestion in soluene 350 (Packard), subjected to double-isotope liquid scintillation counting one wk later (Packard Liquid Scintillation System, Tricarb 2660). The BUI for albumin-bound and free bilirubin was calculated relative to the freely diffusible butanol reference from the respective ratios of tritium to ${ }^{14} \mathrm{C}$ counts in brain and injectate samples. The contribution of residual isotope in the intravascular space represented by sodium pertechnetate was similarly calculated and subtracted from the overall BUI. Equation 1 was used to calculate the BUI for albumin-bound bilirubin. For free bilirubin studies, two further corrections were necessary as described in Results.

$$
\begin{aligned}
& \text { BUI }(\%)=\frac{\frac{\left[{ }^{3} \mathrm{H}\right] \text { bilirubin }}{\left[{ }^{14} \mathrm{C}\right] \text { butanol }} \text { (brain) }}{\frac{\left[{ }^{3} \mathrm{H}\right] \text { bilirubin }}{\left[{ }^{14} \mathrm{C}\right] \text { butanol }} \text { injectate) }} \\
&-\frac{\frac{{ }^{99 \mathrm{~m}} \mathrm{Tc}}{\left[{ }^{14} \mathrm{C}\right] \text { butanol }}}{\frac{{ }^{99 \mathrm{~m}} \mathrm{Tc}}{\left[{ }^{14} \mathrm{C}\right] \text { butanol }} \text { (injectate) }}
\end{aligned}
$$

In situ brain perfusion. The PA $(\mathrm{mL} / \mathrm{s} / \mathrm{g})$ of the blood-brain 
barrier to bilirubin was determined using the in situ brain perfusion technique developed by Takasato et al. (9). The isotope composition of perfusates was $0.5 \mu \mathrm{Ci} / \mathrm{mL}\left[{ }^{3} \mathrm{H}\right]$ bilirubin, $25 \mu \mathrm{Ci} /$ $\mathrm{mL} 99^{\mathrm{m}}$ sodium pertechnetate, and $0.3 \mu \mathrm{Ci} / \mathrm{mL}\left[{ }^{14} \mathrm{C}\right] \mathrm{D}$-alanine. Sodium pertechnetate served as an intravascular marker and $\mathrm{D}$ alanine was used as a control for blood-brain barrier integrity. The $\mathrm{pH}$ of the perfusates was 7.5-8.0. The right common carotid artery was ligated immediately before infusion of the perfusate into the right external carotid artery (Fig. $1 b$ ). The rate of infusion was adjusted to provide a pressure greater than the animal's systolic blood pressure, thereby minimizing systemic blood flow to the right cerebral hemisphere. A flow rate of $5 \mathrm{~mL} / \mathrm{min}$ and a perfusion time of $60 \mathrm{~s}$, terminated by decapitation, were chosen. During the perfusion, systemic blood volume was maintained by withdrawing blood from the femoral artery at the same rate.

Brain tissue samples from the ipsilateral cerebral hemisphere were prepared for $\gamma$ and liquid scintillation counting as described above for single-pass studies. The cerebrovascular PA for bilirubin and D-alanine were calculated using the equation derived by Takasato et al. (9). Equation 2 was used to calculate the PA $(\mathrm{mL} / \mathrm{s} / \mathrm{g})$ for albumin-bound bilirubin. We used the mean values obtained under the same experimental conditions by Takasato et al. (9) for frontal $\left(13.03 \mathrm{~mL} / \mathrm{s} / \mathrm{g} \times 10^{2}\right)$, parietal $(12.76 \mathrm{~mL} / \mathrm{s} /$ $\left.\mathrm{g} \times 10^{2}\right)$, and occipital $\left(11.93 \mathrm{~mL} / \mathrm{s} / \mathrm{g} \times 10^{2}\right)$ cerebral perfusion flow. In the case of free bilirubin studies, two further corrections were necessary as described in Results.

$$
\mathrm{PA}=-\mathrm{Fpf} \ln \left(1-\frac{\mathrm{C} \text { brain }(\mathrm{T})}{\mathrm{T} \cdot \mathrm{Fpf} \cdot \mathrm{Cpf}}\right)
$$

Fpf, regional cerebral perfusion fluid flow $(\mathrm{mL} / \mathrm{s} / \mathrm{g})$; Cpf, tracer concentration in the perfusate $(\mathrm{dpm} / \mathrm{mL}) ; \mathrm{T}$, time duration of perfusion (s); and $\mathrm{C}$ brain (T), brain parenchymal tracer concentration at decapitation (dpm/g).

Statistics. Statistical significance was estimated by $t$ test.

\section{RESULTS}

Single-pass studies. The mean arterial blood pressure, $\mathrm{pH}$, and respiratory blood gas tensions were within the physiologic range and comparable in the two study groups (control injectate and injectate + sulfonamide) at the time of the experiments (Table 1).

Centrifugation of injectate samples demonstrated that, after albumin-binding and membrane dialysis, $4.1 \pm 2.4 \%$ (mean \pm $\mathrm{SD}, n=14$ ) of the tritium activity remained unincorporated. One $h$ after addition of sulfadimethoxine to a portion of the injectate solution, the tritium activity in the filtrate increased by a further $16.5 \pm 4.2 \%$ (mean $\pm \mathrm{SD}, n=18)$. This was attributed to displacement of bilirubin from albumin, and was not found to increase significantly with time over the subsequent $3 \mathrm{~h}$. The total concentration of bilirubin in the albumin-bound control injectates was $493 \pm 157 \mathrm{nmol} / \mathrm{L}$ (mean $\pm \mathrm{SD}, n=14$ ), and in the sulfadimethoxine-treated injectates was $443 \pm 108 \mathrm{nmol} / \mathrm{L}$ (mean $\pm \mathrm{SD}, n=18$ ). The concentration of free bilirubin

Table 1. Mean arterial blood pressure (MABP), pH, and respiratory blood gas tensions (mean $\pm S D$ ) at the time of

\begin{tabular}{|c|c|c|c|c|c|}
\hline Study group & $n$ & $\begin{array}{c}\mathrm{MABP} \\
(\mathrm{mm} \mathrm{Hg})\end{array}$ & $\mathrm{pH}$ & $\begin{array}{r}\mathrm{PaCO}_{2} \\
(\mathrm{~mm} \mathrm{Hg})\end{array}$ & $\begin{array}{c}\mathrm{PaO}_{2} \\
(\mathrm{~mm} \mathrm{Hg})\end{array}$ \\
\hline \multicolumn{6}{|l|}{ Single pass } \\
\hline Control injectate & 14 & $136 \pm 17$ & $7.35 \pm 0.03$ & $43 \pm 3$ & $97 \pm 13$ \\
\hline $\begin{array}{l}\text { Injectate + sulfon- } \\
\text { amide }\end{array}$ & 18 & $139 \pm 17$ & $7.34 \pm 0.04$ & $42 \pm 5$ & $95 \pm 9$ \\
\hline \multicolumn{6}{|l|}{ In situ perfusion } \\
\hline Control perfusate & 13 & $109 \pm 18$ & $7.35 \pm 0.06$ & $43 \pm 6$ & $101 \pm 16$ \\
\hline $\begin{array}{l}\text { Perfusate }+ \text { sulfon- } \\
\text { amide }\end{array}$ & 12 & $105 \pm 13$ & $7.35 \pm 0.05$ & $41 \pm 8$ & $98 \pm 16$ \\
\hline
\end{tabular}

displaced by the sulfonamide was $68 \pm 28 \mathrm{nmol} / \mathrm{L}$ (mean $\pm \mathrm{SD}$, $n=18$ ).

The measured BUI for bilirubin in the control injectates was $1.8 \pm 0.8 \%$ (mean $\pm \mathrm{SD}, n=14$ ). This could be more than accounted for by the percentage of tritium activity shown to be dialyzable in vitro, and was therefore attributed to unincorporated tritium in the injectate. Two corrections were therefore made in calculating the uptake of free bilirubin from sulfonamide-treated injectates. First, the corresponding apparent uptake from the control portion of the prepared solution was subtracted. The BUI was then calculated as a percentage of the measured free bilirubin available in individual injectates, i.e. the percentage of $\left[{ }^{3} \mathrm{H}\right]$ bilirubin demonstrated in vitro to be unbound by virtue of being dialyzable. There was no significant difference between the BUI determined in frontal, parietal, and occipital lobes and a mean value was calculated for the cerebral hemisphere in each individual animal. The BUI for free bilirubin was $28.5 \pm 9.3$ (mean $\pm \mathrm{SD}, n=18$ ) (Fig. 2).

In situ brain perfusion studies. The mean arterial blood pressure, $\mathrm{pH}$, and respiratory blood gas tensions were within the physiologic range and comparable in the two study groups (control perfusates and perfusates + sulfonamide) at the time of the experiments (Table 1).

Centrifugation of perfusate samples demonstrated that after albumin-binding and membrane dialysis $3.3 \pm 1.1 \%$ (mean \pm $\mathrm{SD}, n=13$ ) of the tritium activity remained unincorporated. One $h$ after addition of sulfadimethoxine to a portion of the perfusate solution, the tritium activity in the filtrate increased by a further $17.3 \pm 6.9 \%$ (mean $\pm \mathrm{SD}, n=12$ ). This was attributed to displacement of bilirubin from albumin. The total concentration of bilirubin in the control perfusates was $67 \pm 19 \mathrm{nmol} / \mathrm{L}$ (mean $\pm \mathrm{SD}, n=13$ ) and in the sulfadimethoxine-treated perfusates was $65 \pm 18 \mathrm{nmol} / \mathrm{L}$ (mean $\pm \mathrm{SD}, n=12$ ). The concentration of free bilirubin displaced by the sulfadimethoxine was $11 \pm 4 \mathrm{nmol} / \mathrm{L}$ (mean $\pm \mathrm{SD}, n=12$ ). The measured PA value for bilirubin in the control perfusates was $1.91 \pm 0.98 \times 10^{-4}$ $\mathrm{mL} / \mathrm{s} / \mathrm{g}$ (mean $\pm \mathrm{SD}, n=13$ ). This could be accounted for by unincorporated tritium in the perfusate. The PA value for free bilirubin in sulfonamide-treated perfusates was calculated using the same corrections as described for the BUI, thus allowing for unincorporated tritium and the percentage of albumin-bound bilirubin shown in vitro to have been displaced in individual perfusates. There was no significant difference in the PA values obtained for the frontal, parietal, and occipital lobes, and a mean value was therefore calculated for the cerebral hemisphere as a

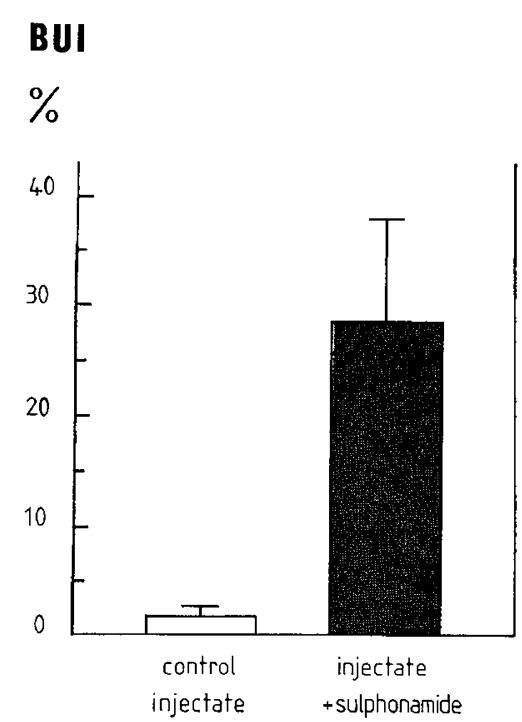

Fig. 2. The mean BUI values for control and sulfonamide-treated injectates. Error bars represent $1 \mathrm{SD}$. 
whole. The cerebrovascular PA value for free bilirubin was 54.84 $\pm 36.38 \times 10^{-4} \mathrm{~mL} / \mathrm{s} / \mathrm{g}$ (mean $\pm \mathrm{SD}, n=13$ ) (Fig. 3 ).

The PA values for $\mathrm{D}$-alanine, added to the control and sulfonamide-treated perfusates, were $5.02 \pm 3.60 \times 10^{-4} \mathrm{~mL} / \mathrm{s} / \mathrm{g}$ (mean $\pm \mathrm{SD}, n=13)$ and $5.80 \pm 4.06 \times 10^{-4} \mathrm{~mL} / \mathrm{s} / \mathrm{g}($ mean $\pm \mathrm{SD}, n$ $=12$ ) (NS), respectively. Although there are no other reported values for the PA of D-alanine for comparison, it would be expected to be low as the $\mathrm{Km}$ for L-alanine is $183 \mu \mathrm{mol} / \mathrm{mL}(10)$. In contrast to other amino acids for which PA values have been determined, our value for $\mathrm{D}$-alanine is, for example, approximately $20 \%$ of that quoted for phenylalanine (11).

\section{DISCUSSION}

Difficulties arising from the biochemistry of the bilirubin molecule and the limitations imposed by the experimental techniques used require discussion before interpretation of the results in the context of the newborn infant.

As commercially available radiolabeled bilirubin was of too low a sp act to meet the requirements of the study, tracer of the appropriate $\mathrm{sp}$ act had to be synthesized. Care is required with regard to ambient lighting and the $\mathrm{pH}$ of solutions containing bilirubin in view of bilirubin's chemical instability, ready isomerisation, photosensitivity, and low aqueous solubility. In vitro, and particularly at acid $\mathrm{pH}$, the isomers bilirubin III- $\alpha$ and XIII$\alpha$ are formed by cleavage of bilirubin IX- $\alpha$ at the central methylene bridge with subsequent recombinations of the dipyrrole units. Crystalline bilirubin (Sigma Chemical Co., St. Louis, MO, cat. no. B4126) contains approximately $1-1.5 \%$ of the III- $\alpha$ and $5-7 \%$ of the XIII- $\alpha$ isomers. These isomers accumulated further during the synthesis of $\left[{ }^{3} \mathrm{H}\right]$ bilirubin, comprising approximately $15 \%$ of the product, and were removed by thin-layer chromatography. On retrieval of $\left[{ }^{3} \mathrm{H}\right]$ bilirubin from storage vials and during preparation of the injectate/perfusate solutions, subdued lighting was used and an alkaline pH $(>9.0)$ was maintained until adjustment to $\mathrm{pH} 7.5-8.3$ before purification and use. The high $\mathrm{pH}$ used was a necessary precaution in view of the low aqueous solubility of bilirubin in the physiologic range. At $\mathrm{pH} 7.4$, the solubility of bilirubin dianion is $7 \mathrm{nmol} / \mathrm{L}(2)$. The radiochemical purity of stored $\left[{ }^{3} \mathrm{H}\right]$ bilirubin was documented to the limits of

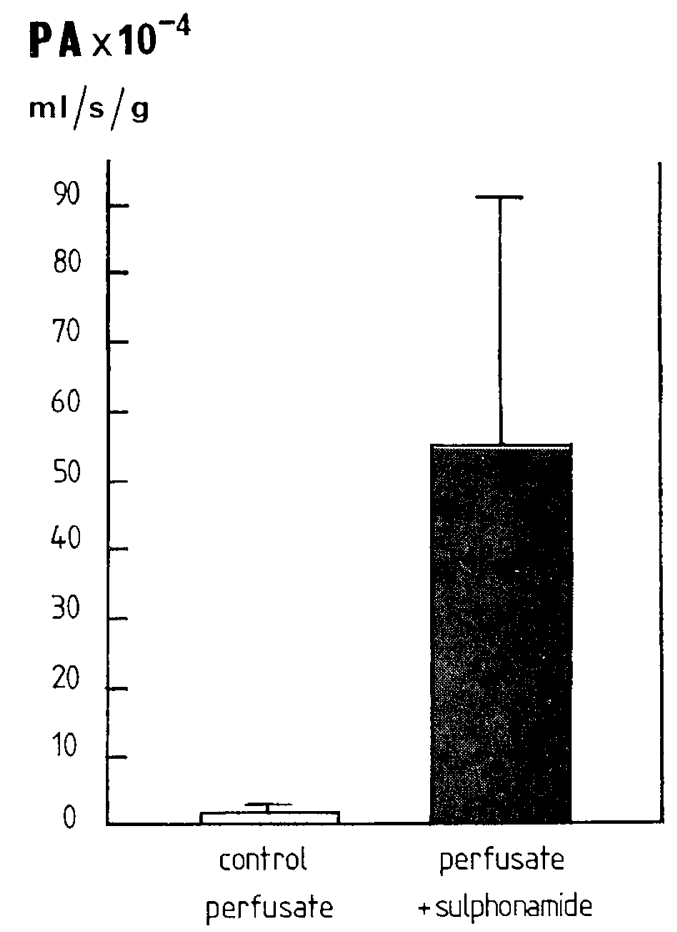

Fig. 3. The mean PA values for control and sulfonamide-treated perfusates. Error bars represent $1 \mathrm{SD}$. the techniques available. The proportion of activity that remained dialyzable in the presence of a 20 -fold $M$ excess of albumin, which would effectively bind all bilirubin, was assumed to be unincorporated tritium, and attempts were made to remove this by prolonged membrane dialysis. Membrane filtration cones with a retention cutoff of $25000 \mathrm{~mol} \mathrm{wt}$ were chosen to assess the efficiency of this purification process and the displacing effect of the sulfonamide. They were used at low relative centrifugal force to avoid or minimize protein leakage.

The small percentage of apparently unincorporated tritium activity quantified in the control injectates and perfusates more than accounted for the uptake and permeability values observed in the control (albumin-bound bilirubin) experiments. The need for membrane dialysis to purify $\left[{ }^{3} \mathrm{H}\right]$ bilirubin immediately before use dictated the addition of a displacing agent to the injectate/ perfusate to provide free bilirubin. Any direct effect of the sulfonamide on blood-brain barrier permeability was excluded in the in situ brain perfusion studies by demonstration of the constancy of the D[U- $\left.{ }^{14} \mathrm{C}\right]$-alanine PA product in the control and sulfonamide-treated groups. D-alanine was used as a nontransported substance of a mol wt and low lipid solubility comparable to bilirubin.

After Oldendorf's original description of single-pass carotid bolus studies in the rat (7), the technique was modified. The traditional $\left[{ }^{3} \mathrm{H}\right]$ water reference was replaced by more diffusible substances, and the study duration of $15 \mathrm{~s}$ reduced. Butanol was used in these studies since it is largely extracted into brain tissue within a single capillary transit time (less than $1 \mathrm{~s}$ ) and leaves the brain slowly at a rate of $1.1 \% / \mathrm{s}(12)$. To limit this efflux, which will tend to overestimate the BUI of the test substance, the time to decapitation was reduced to $5 \mathrm{~s}$. A further advantage of reducing the study time is to minimize the effects of recirculation of tracer that occurs after $7-8 \mathrm{~s}(8)$. Some $96 \%$ of the injectate solution clears the brain by $2 \mathrm{~s}$, and there is very little remaining at $5 \mathrm{~s}(8)$. Correction for residual tracer in the vascular space was made in these experiments by inclusion of nondiffusible ${ }^{99 \mathrm{~m}} \mathrm{Tc}$. A further important consideration when using single-pass techniques to study the uptake of albumin-bound substances is the degree of mixing that may occur between the injected bolus and circulating rat plasma. Pardridge et al. (13) have documented that the upper limit for bolus mixing is $5.5 \%$. To minimize the effect of bolus mixing in the free bilirubin uptake studies, an intraperitoneal loading dose of $200 \mathrm{mg} / \mathrm{kg}$ sulfafurazole was given.

The in situ brain perfusion technique used in the second series of experiments provides a quantitative measure of blood-brain barrier permeability. Initial studies using the in situ technique (9) endeavoured to maintain normal cerebral function and metabolism by using oxygenated perfusates containing glucose. Such precautions are unnecessary for short duration perfusions of one hemisphere. Greenwood et al. (14) have demonstrated maintenance of blood-brain barrier integrity for up to $30 \mathrm{~min}$ during in situ perfusion of the whole brain with a solution containing the metabolic inhibitor 2,4-dinitrophenol.

The single-pass and in situ perfusion experiments both demonstrate a significant permeability of the microvasculature of the adult rat cerebral hemisphere to unbound bilirubin. The methodology is unsuitable for studying areas of the brain such as the basal ganglia and cerebellum, but regional values were obtained from the frontal, parietal, and occipital lobes. In neither set of experiments was there any significant difference between the uptakes of these three brain regions. The BUI observed for free bilirubin of $28.5 \pm 9.3 \%$ is considerably greater than that reported for aqueous soluble polar compounds such as mannitol, but very much less than that for highly lipid-soluble compounds such as propranolol and caffeine, which attain BUI in excess of $70 \%$. Similarly, the PA value for free bilirubin of $54.84 \pm 36.38 \times$ $10^{-4} \mathrm{~mL} / \mathrm{s} / \mathrm{g}$ indicates that the permeability of the rat bloodbrain barrier to free bilirubin is significant because it approaches that of molecules such as antipyrine with a PA in the region of 
$140 \times 10^{-4} \mathrm{~mL} / \mathrm{s} / \mathrm{g}(9)$. Both the BUI and PA product are far greater than would be expected for a molecule that exhibits such low lipid solubility in vitro (2).

Albumin-stripping (the dissociation of bilirubin from albumin during brain capillary transit) is unlikely to have contributed significantly to these results. The capillary transit time in the rat is about $1 \mathrm{~s}$, and applying a dissociation rate constant for bilirubin of $8.8 \times 10^{-3} / \mathrm{s}(15)$ would provide $0.88 \%$ of stripped bilirubin available for uptake. Assuming the sulfonamide does not affect the dissociation rate constant significantly, such a value would be masked by the results for BUI and PA of free bilirubin but may have contributed to the apparent control values. Two other variables that may have had a greater influence on the results are those of $\mathrm{pH}$ and temperature. The $\mathrm{pH}$ will influence the relative proportions of bilirubin subspecies, namely the dianion, acid-salt, and acid. At the $\mathrm{pH}$ range of the injectates/perfusates (7.5-8.3), bilirubin dianion would predominate, and the acidsalt and acid, which are the subspecies implicated in membrane binding, would be in very low concentration. Although the binding of bilirubin to albumin is independent of $\mathrm{pH}$ within the physiologic range, the binding of bilirubin to cell membranes is enhanced at lower $\mathrm{pH}$ (16). Despite these considerations, no significant correlation could be demonstrated between the $\mathrm{pH}$ of the solutions and PA or BUI values. The injectate and perfusate solutions were not buffered and may have been altered in the direction of more physiologic $\mathrm{pH}$ values during transit.

Temperature significantly influences bilirubin binding to albumin. Ideally, all manipulations of the solutions, including centrifugation and administration, would have been performed at $37^{\circ} \mathrm{C}$. Consideration of the potential for increased degradation of $\left[{ }^{3} \mathrm{H}\right]$ bilirubin at this temperature prompted the use of room temperature throughout. In the case of the single-pass studies, it is likely that the injectate bolus temperature would tend to equilibrate with body temperature during passage. This would be unlikely to occur with the in situ perfusions over $60 \mathrm{~s}$, during which right cerebral hemisphere cooling may have occurred. If the temperature of the injectate in single-pass studies had been raised to $37^{\circ} \mathrm{C}$ during passage, the free bilirubin content would theoretically have increased by up to 3 -fold (17). The BUI value, based on the in vitro measurement of free bilirubin at room temperature, could as a result be an overestimate by the same factor. Overestimation of both the BUI and PA values may also have resulted from binding of free bilirubin to the membrane cones during centrifugation. Bilirubin binding to membranes such as Sephadex is known to occur at lower pH (18), but the use of solutions with a $\mathrm{pH} \geq 7.5$ may have limited this potential error in our experiments.

There are several constraints to direct extrapolation of these results to the mode of entry of bilirubin in the human newborn brain. The differences among species, developmental age, and region of the brain studied all merit comment. The rat was used because both experimental techniques have been developed and validated in that species. Rat albumin, however, differs in its binding characteristics with bilirubin; for this reason human albumin was used in the preparation of injectates and perfusates. Technical consideration dictated the use of adult rats. Animal studies of the newborn brain (19) have demonstrated a longer capillary transit time, which, if it exceeds the dissociation time of an albumin-bound compound, will increase brain uptake. Such albumin-stripping has been demonstrated in the case of the protein-bound anticonvulsants phenobarbitone and phenytoin in newborn as opposed to adult rabbits (19), but, as previously discussed, would not contribute significantly in the case of bilirubin, which is more tightly bound to albumin. Conversely, the increased blood flow to subcortical regions of the brain has been proposed as the mechanism of increased bilirubin deposition in those areas (20). A comparative study of areas such as the basal ganglia and cerebellum was not feasible using the techniques described.

The results do, however, demonstrate that despite the evidence of bilirubin's very low lipid solubility in vitro (2), its behavior in vivo in relation to the cerebral microvasculature corresponds to that of a lipid soluble molecule. This may be the result of an interaction between bilirubin and membrane phospholipids such that lipid soluble complexes of bilirubin are formed (2). Alternatively, Wennberg (21) has recently suggested that the tissue binding of bilirubin results from detergent properties of the free bilirubin acid-salt.

The use of $\left[{ }^{3} \mathrm{H}\right]$ bilirubin IX $-\alpha$ of high sp act in these experiments allowed the study of blood-brain barrier permeability to unbound bilirubin at concentrations known to exist in newborn infants. Although the effect of exposure of the brain to such levels for longer duration was not addressed by this study, estimation of the rate of influx of free bilirubin using these results provides values well below the rate at which brain bilirubin oxidase would be expected to metabolize the molecule (22). This would suggest that contributory factors may be necessary to confer neurotoxicity. For instance, the metabolism of bilirubin by brain mitochondrial bilirubin oxidase may be insufficient under conditions of hypoxia and therefore allow the pigment to accumulate to toxic levels. This mechanism of bilirubin neurotoxicity has been proposed by Brodersen (23) and may explain the combined effect of hypoxia and hyperbilirubinemia in disrupting brain energy metabolism in guinea pig cerebral hemisphere slices studied in vitro (24). Hypoxia in common with asphyxia, hypercapnia, hypertension, and hyperosmolality may also exacerbate bilirubin encephalopathy by disruption of the blood-brain barrier. The resultant increase of influx of bilirubin may overwhelm the clearance capacity of brain bilirubin oxidase, and allow bilirubin to attain concentrations that promote precipitation of bilirubin acid on intracellular organelles. Such acute effects of blood-brain barrier opening in the presence of hyperbilirubinemia have been demonstrated in a rat model of hyperosmolar opening (25), both in terms of electrophysiologic (26) and ${ }^{31} \mathrm{P}$ nuclear magnetic resonance spectrographic (27) evidence of cerebral neurotoxicity.

In conclusion, these results provide the first quantitation of blood-brain barrier permeability to bilirubin, and demonstrate significant permeability to free, but not albumin-bound, bilirubin.

Acknowledgments. The authors thank Professor R. Brodersen, Institute of Medical Biochemistry, University of Aarhus, Denmark, Professor M. W. B. Bradbury, Department of Physiology, King's College, London, and Dr. D. W. Hutchinson, Department of Chemistry and Molecular Sciences, University of Warwick, Coventry for technical advice. We thank Minakshi Joshi for providing excellent technical assistance, Roche Products Limited for supplying reagents, and Gail Davies for preparing the manuscript.

\section{REFERENCES}

1. Saunders NR 1986 Development of human blood-CSF-brain barrier. Letter. Dev Med Child Neurol 28:261-262

2. Brodersen R 1978 Bilirubin solubility and interaction with albumin and phospholipid. J Biol Chem 254:2364-2369

3. Diamond I, Schmid R 1966 Experimental bilirubin encephalopathy. The mode of entry of bilirubin $-{ }^{14} \mathrm{C}$ into the central nervous system. $\mathrm{J}$ Clin Invest 45:678-689

4. McDonagh AF, Assisi F 1972 The ready isomerisation of bilirubin IX- $\alpha$ in aqueous solution. Biochem J 129:797-800

5. McDonagh AF, Palma LA 1980 Preparation and properties of crystalline biliverdin IX- $\alpha$. Biochem J 189:193-208

6. Hutchinson DW, Wilkes NM, Au HYN $1980{ }^{3} \mathrm{H}$-labelled bilirubin and biliverdin. J Labelled Comp Radiopharm 18:1401-1404

7. Oldendorf WH 1970 Measurement of brain uptake of radiolabelled substances using a tritiated water internal standard. Brain Res 24:372-376

8. Hardebo JE, Nilsson B 1979 Estimation of cerebral extraction of circulating compounds by the brain uptake index method: influence of circulation time, volume injection, and cerebral blood flow. Acta Physiol Scand 107:153-159

9. Takasato Y, Rapoport ST, Smith QR 1984 An in situ brain perfusion technique to study cerebrovascular transport in the rat. Am J Physiol 247:H484-H493

10. Smith QR, Momma S, Aoyagi M, Rapoport SI 1987 Kinetics of neutral amino acid transport across the blood-brain barrier. J Neurochem 49:1651-1658 
11. Momma S, Aoyagi M, Rapoport SI, Smith QR 1987 Phenylalanine transport across the blood-brain barrier as studied with the in situ brain perfusion technique. J Neurochem 48:1291-1300

12. Pardridge WM, Mietus LJ 1979 Palmitate and cholesterol transport through the blood-brain barrier. J Neurochem 34:463-466

13. Pardridge WM, Landaw EM, Miller LP, Braun LD, Oldendorf WH 1985 Carotid artery injection technique: bounds for bolus mixing by plasma and by brain. J Cereb Blood Flow Metab 5:576-583

14. Greenwood J, Luthert PJ, Pratt OE, Lantos PL 1985 Maintenance of the integrity of the blood-brain barrier in the rat during an in situ saline-based perfusion. Neurosci Lett 56:223-227

15. Svenson A, Holmer E, Anderson L-O 1974 A new method for the measurement of dissociation rates for complexes between small ligands and proteins as applied to the palmitate and bilirubin complexes with serum albumin Biochim Biophys Acta 342:54 59

16. Nelson T, Jacobsen J, Wennberg RP 1974 Effect of $\mathrm{pH}$ on the interaction of bilirubin with albumin and tissue culture cells. Pediatr Res 8:963-967

17. Jacobsen $J 1977$ Studies of the affinity of human serum albumin for binding of bilirubin at different temperatures and ionic strength. Int J Pept Protein Res 9:235-239

18. Chunga F, Lardinois $R 1971$ Separation by gel filtration and microdetermination of unbound bilirubin. Acta Paediatr Scand 60:27-32

19. Cornford EM, Pardridge WM, Braun LD, Oldendorf WH 1983 Increased blood-brain barrier transport of protein-bound anticonvulsant drugs in the newborn. J Cereb Blood Flow Metab 3:280-286

20. Burgess GH, Oh W, Bradlid D, Brubakk A-M, Cashore WJ, Stonestreet BS 1985 The effects of brain blood flow on brain bilirubin deposition in newborn piglets. Pediatr Res 19:691-696

21. Wennberg RP 1988 The importance of free bilirubin acid salt in bilirubin uptake by erythrocytes and mitochondria. Pediatr Res 23:443-447

22. Brodersen R, Bartels P 1969 Enzymatic oxidation of bilirubin. Eur J Biochem 10:468

23. Brodersen $R 1980$ Bilirubin transport in the newborn infant, reviewed with relation to kernicterus. J Pediatr 96:349-356

24. Ives NK, Cox DWG, Gardiner RM, Bachelard HS 1988 The effects of bilirubin on brain energy metabolism during normoxia and hypoxia: an in vitro study using ${ }^{31} \mathrm{P}$ nuclear magnetic resonance spectroscopy. Pediatr Res 23:569-573

25. Levine RL, Fredericks WR, Rapoport SI 1982 Entry of bilirubin into the brain due to opening of the blood-brain barrier. Pediatrics 69:255-259

26. Wennberg RP, Hance AJ 1986 Experimental bilirubin encephalopathy: im. portance of total bilirubin, protein binding, and blood-brain barrier. Pediatr Res 20:789-792

27. Ives NK, Bolas NM, Gardiner RM 1989 The effects of bilirubin on brain energy metabolism during hyperosmolar opening of the blood-brain barrier: an in vivo study using ${ }^{31} \mathrm{P}$ magnetic resonance spectroscopy. Pediatr Res 26:356-361 